\title{
INEFFICIENCY, PUBLIC ENTERPRISE AND PRIVATISATION
}

\author{
Ray REES \\ University of Guelph, Guelph, Ont, Canada NIG $2 W I$
}

\section{Introduction}

There is a general perception, based upon casual observation and some systematic empirical study, that public enterprises are inefficient. ${ }^{1}$ This paper takes this to be true, and is concerned with the problem of providing a rigorous analysis and explanation of this inefficiency. ${ }^{2}$ Privatisation, which, in the U.K. at least has received its primary impetus from political and ideological motivations, ${ }^{3}$ has also been supported by some economists ${ }^{4}$ because it is seen as a way of correcting these inefficiencies. To test this argument, the analysis of public enterprise inefficiency will be extended in this paper to the issue of privatisation.

The analysis is an application of the theory of agency, ${ }^{5}$ and in particular makes extensive use of the model of the adverse selection or incentive compatability problem. ${ }^{6}$ Privatisation is regarded essentially as a change in the structure of this principal-agent model.

Briefly, the adverse selection agency model deals with the situation in which an agent is supposed to take decisions on behalf of a principal, but has his own objectives which may lead him to act in his own as opposed to the principal's interests. If the principal possessed all the information held by the agent, such conflict would not be possible. However, in the adverse selection model the agent possesses some 'private' information which is not available to the principal. The agent will report a message concerning this

\footnotetext{
'For example, see the papers by Bös, and by Perelman and Pestieau, elsewhere in this volume.

${ }^{2}$ It may be useful to distinguish between 'short-run' inefficiency, in the sense of wasteful use of variable inputs, especially labour, and 'long-run' inefficiency, in the sense of 'great planning disasters', major inefficiencies in investment planning. For interesting discussion of the latter, possibly more important type of inefficiency, see Henderson (1977).

${ }^{3}$ The aims of widening the base of share ownership among households, and of "rolling back the frontiers of the public sector', as well as the short term political advantage of disguising part of government borrowings as the sale of shares in privatised companies have all been relevant here.

${ }^{4}$ Particularly S.C. Littlechild and M. Beesley.

${ }^{3}$ For general surveys of this theory see MacDonald (1984) and Rees (1985a).

${ }^{\circ} \mathrm{A}$ very thorough treatment of this problem in a form directly relevant for the concerns of this paper is given in Guesnerie and Laffont (1984). See also Caillaud et al. (1985).
} 
information, following which decisions are taken and utilities determined, but the report may be biased by the self interest of the agent. The problem for the principal is then to devise a contract ${ }^{7}$ which is the best possible given that the agent will optimise for himself under whatever contract is specified. The main result ${ }^{8}$ can be very loosely put as follows: the optimal solution for the principal is in effect to bribe the agent to report his private information truthfully ${ }^{9}$ by giving him more utility than he would obtain in the situation where the principal was fully informed. ${ }^{10}$ In effect, the agent obtains a rent to the monopoly of his private information.

An approach to explaining public enterprise inefficiency by use of agency theory then has to show how a model can be formulated which appears to capture the main elements of the real situation and then to show how the general nature of the solution to the adverse selection problem implies the particular kinds of inefficiency which appear to have been identified. This is the task of the following section.

\section{Public enterprise as agency}

The identification of the 'government' or 'planner' as the principal and the enterprise as agent begs a number of questions ${ }^{11}$ but can be justified as a fruitful simplification. As a positive proposition, it is certainly not realistic to assume that the planner is concerned only with allocative efficiency and, possibly, profitability, ${ }^{12}$ but if we are concerned with explaining inefficiency then again it is useful to model the principal as if he were. ${ }^{13}$ Main interest then centres on the behaviour of the agent, the enterprise, for which a positive model has to be constructed.

The public enterprise is viewed as a coalition of management and workers. Management prefers more output to less, ${ }^{14}$ the workers, or rather their union, prefer higher wages and employment levels to lower. Negotiation

'This should be loosely interpreted as any set of rules and procedures for regulating the agent's behaviour and determining his pay-off.

${ }^{8}$ Full analysis of this result is widely available in the literature.

'This is the so-called 'revelation principle'. See Myerson (1979).

${ }^{10} \mathrm{Or}$, strictly speaking, for almost all values of the agent's private information.

"For example it treats cach - government and enterprise - as if it were a single individual and finesses the problem of articulation of their preferences. It also ignores the argument that we have a hierarchy, with 'households' as the ultimate principal and 'government' as a kind of intermediate agent. Both these issues deserve further analysis.

${ }^{12} \mathrm{~A}$ positive study would have to take a realistic view of the motivations of politicians and bureaucrats, in terms perhaps of power, votes, and so on.

${ }^{13}$ This permits identification of the loss of efficiency in terms of the sacrifice made by the principal to elicit truthful revelation. The drawback to this approach is that it does not permit analysis of inefliciencies which may arise because of government objectives which depart from allocative efficiency - inefficiency is entirely the fault of the enterprise, as it were.

${ }^{14}$ Output seems a useful way to characterize 'size', and managers are regarded as would-be size maximizers. 
between them establishes an enterprise utility function which could be written as $u(y, w, l)$, where $y$ is total output, $w$ is the wage rate, and $l$ is employment. ${ }^{15}$ The enterprise faces the usual kind of constraints arising out of market demand and supply conditions and technology, with the production function given by $f(k, l, \theta)$, where $k$ is capital and $\theta$ is a 'productivity parameter'. It also faces control constraints, which represent the process by which government seeks to influence the outcome. In the U.K., these take the form essentially of a minimum constraint on profit, $\pi \geqq \pi^{0}$, and a maximum constraint on capital, ${ }^{16} k \leqq k^{0}$. Then, for given values of $\theta, \pi^{0}$ and $k^{0}$ the enterprise decisions can be regarded as generated by the procedure of maximising its utility ${ }^{17}$ subject to market, technology, and control constraints. The details of the results of this maximisation are not of immediate interest here, ${ }^{18}$ though we can note that they imply predictions which are consistent with empirical observation of the behaviour of public enterprises. ${ }^{19}$ More to the point, the solution implies an indirect utility function $v\left(k^{0}, \pi^{0}, \theta\right)$, which expresses the enterprise or agent's maximised utility as a function of the control constraint values and the productivity parameter, with $\partial v / \partial k^{0} \geqq 0, \partial v / \partial \pi^{0}<0$, and $\partial v / \partial \theta>0$.

We are now in a position to formulate the agency problem. If the principal, the government, possessed full information about market and technological conditions, it could instruct the agent to set first-best levels of price, output, capital, labour and wage rates. If allocative efficiency were the only concern this would imply marginal cost pricing, labour receiving its opportunity cost wage, and inputs chosen to minimize costs. If profitability also matters, we would have a Ramsey pricing rule. However, realistically, government does not possess complete information. There is an information asymmetry, which here can be modelled by assuming that the enterprise knows its true productivity, $\theta$, while the government does not, but possesses only some prior probability density on its value. In other words, we have an adverse selection type of agency problem. The solution of this problem is perfectly standard $^{20}$ [see Rees $\left.(1985,1986 a)\right]$ and has the following implications. In order to induce the enterprise to reveal its true productivity, loosely speaking, the government must give it more capital and a lower profit constraint than it would in the full information first-best case. Hence, capital

\footnotetext{
${ }^{13}$ Any of these variables could also obviously be specified as a vector, or alternatively as an index number.

${ }^{16} \mathrm{This}$ arises out of the fact that investment is typically subject to rationing procedures.

${ }^{17}$ Where the derivatives of the utility function essentially reflect some kind of internal bargaining process in the enterprise. Again this aspect of the model would certainly be worth further study.

${ }^{18}$ They are given in Rees (1984a).

${ }^{19} \mathrm{See}$ for example the discussion in Rees (1987a).

${ }^{20}$ Though an assumption has to be made about the form of the indirect utility function $v(-,-,-)$ to guarantee a 'single-crossing property'. The implication of this assumption for the nature of the enterprise utility, demand and production functions is an open question.
} 
productivity and overall profitability are lower as a result of the information asymmetry. Note that this inefficiency is, by definition of the problem, minimised. It is the smallest possible departure from the full information firstbest consistent with the information asymmetry.

To summarize, what kind of explanation of public enterprise inefficiency does the modelling approach outlined in this section give? It suggests first that, relative to any given set of control constraints, wages will be higher than competitive levels and employment will be higher than the level that minimizes costs at the implied ratio of wages to other input prices. Labour productivity will be lower than at a cost minimizing solution. This is essentially because the enterprise is a monopoly and so generates rents, some of which are captured by the workers who organise themselves and acquire bargaining strength for that purpose. The nature of the union's preferences and the structure of the bargaining process imply that capture of these rents is done in a way that entails inefficiency - there is a dead-weight loss entailed by the process of rent capture. ${ }^{21}$

Secondly, it suggests that the slackness of the profit constraint and low returns to investment which are taken to be characteristic of public enterprise (and which are of course interrelated with the low labour productivity, as a formal examination of the model makes clear) are an inescapable consequence of information asymmetry - the fact that the public enterprise knows its true production possibilities and hence productivities and costs, while the government does not. The inefficiency associated with this fact - the bribe that has to be paid to induce truthful revelation - can only be minimised, and not eliminated.

Although it does I think give useful insights and ideas, the analysis I have just set out is not the full story, essentially because it is not really descriptive of the actual control process. In reality, the 'agency problem' - the problem of incentive compatibility - is not solved. The government in fact allows itself to be manipulated by the enterprise and accepts false, or, better, excessively optimistic, information about production possibilities. In a paper in which I have tried to analyse how the system actually does work [Rees (1984b)], I have shown that something called profit consistency plays the key role here, and the lack of it in the actual planning process leads inefficiency to be even greater than if the agency problem were solved.

By profit consistency I mean simply that given the value of $\theta$ reported by the enterprise, and the capital allocation set, the profit target is the amount of profit generated by that amount of capital for that value of $\theta$. In other words, the enterprise is required to earn the profit it says it can earn given the $\theta$ it has reported and the capital allocated.

\footnotetext{
${ }^{21}$ Of course, exactly the same conclusion would apply if the enterprise were a private monopoly. What differs is the tightness of the profit constraint under private as opposed to public enterprise, and the possibility that unions receive political support in their efforts at rent capture in the public sector.
} 
The solution of the incentive compatibility problem in the agency model is certainly profit consistent, and indeed this is a fundamental attribute of it. For each $\theta$ reported there is a corresponding pair of values of the constraints, $\left(k^{0}(\theta), \pi^{0}(\theta)\right)$, where $\pi^{0}(\theta)$ must be generated from $k^{0}(\theta)$. In the actual process of public enterprise investment planning and control, however, this consistency does not usually exist: public enterprises are not constrained to earn the returns they say they will earn when they submit their investment plans (report $\theta$ ). The major reason for this is the typically long gestation periods of investment and the fact that profit constraints are set for a short period ahead in the light of the conditions determining the total profitability of the enterprise at the time. Thus suppose an enterprise submits a plan for a large capital expenditure on the basis of a forecast of high productivity, high demand and a high rate of return, and suppose that this is accepted. ${ }^{22}$ Then, after, say, a five year gestation period, the project comes on stream, but with lower productivity and demand than predicted. It would not usually happen that the enterprise would then be constrained to earn the profit implied by its original forecast, even though incentive compatibility requires that it must be. ${ }^{23}$ Thus there are no penalties for over-optimistic forecasting, and this will therefore be the result. The absence of profit consistency implies that public enterprise inefficiency will be still greater than the inescapable minimum which the analysis of the agency model identifies as stemming from the information asymmetry at the root of the problem - we have an additional element in the explanation of inefficiency to those suggested by the agency model.

\section{Privatisation}

By privatisation I mean the vesting of the assets of a public enterprise in a limited liability company and the sale of at least a simple majority of the company's shares to private investors. Certainly, the perception of the inefficiencies of public enterprise has lent some support to the idea that privatisation may provide a more efficient alternative. On the other hand given that, in the major cases, ${ }^{24}$ the policy implies the replacement of public by private monopoly, there is clearly a need to address the issue of whether the political goals are likely to be achieved at a cost in terms of loss of economic efficiency. ${ }^{25}$

In this paper I take the view that privatisation essentially represents a change in structure of the agency model, and so how is this change to be

\footnotetext{
${ }^{22}$ This acceptance of course stems from the information asymmetry.

${ }^{23}$ Solution of the agency problem requires that the enterprise actually be allocated the pair $\left(k^{\circ}(\theta), \Pi^{\circ}(\theta)\right)$.

${ }^{24}$ The privatisation of the major utilities such as telecommunications, gas, airports, and the projected privatisation of electricity and water supply.

${ }^{25}$ Supporters of privatisation argue of course that there will be no economic costs, only benefits. For a general discussion of the arguments on either side see Rees (1986b).
} 
specified? I would argue that in the short run, there will be no change in the enterprise utility function - after all, the identities of the members of the coalition remain unchanged, while there is no reason in general to expect a reduction in trade union bargaining strength. Likewise, the market and technological constraints are not changed by privatisation as such. The identity of the 'principal' now changes to that of the regulatory agency ${ }^{26}$ though, again, if we are interested in the analysis of enterprise inefficiency, we can take the principal's utility function to remain unchanged. ${ }^{27}$ The initial impact of privatisation must therefore result from changes in the control constraints, which in turn reflect changes in the underlying processes of planning, supervision and control.

First, the profit and capital constraints that existed under (full) public ownership disappear, and are replaced by a much tighter stock marketdetermined profit constraint. The enterprise will now have free access to the capital market, but its investment planning process will have to be profit consistent - persistent appraisal optimism of the sort that characterises public enterprise would be severely punished by the stock market share valuation mechanism. However, these impact effects of privatisation are not necessarily welfare-improving. ${ }^{28}$ As the profit constraint tightens, both management and workers have to give up utility, to an extent determined by relative bargaining strengths in the coalition. That is, slack in the form of excessive employment and wage rates is reduced, but prices rise and outputs fall, the former increasing welfare, ${ }^{29}$ the latter reducing it.

Enter the regulatory process. In implicit recognition of the mixed effects of privatisation, regulatory frameworks have been established for each of the major privatised enterprises, the main feature of which for present purposes I take to be the rule constraining the permissible rate of price increase, ${ }^{30}$ the so-called ' $R P I-x$ ' rule. If this is binding, and the evidence suggests that it has been, ${ }^{31}$ then in effect this increases the pressure on slack exerted by the tightening profit constraint and increases the probability that privatisation will indeed be welfare improving.

This then raises the question: how was the regulatory constraint on the

\footnotetext{
${ }^{20} \mathrm{Again}$, this begs a number of questions, since government continues to have an interest in the activities of the enterprise and shareholders could also be regarded as in some sense 'principals'.

${ }^{27}$ Indeed, to assume concern only with allocative efficiency may involve smaller loss of realism in the case of the regulatory agency than it does in the case of government.

${ }^{28}$ In the sense that they increase the value of a partial equilibrium welfare measure, the sum of producers' and consumers' surpluses.

${ }^{29} \mathrm{Again}$ in the sense of the usual partial equilibrium welfare measure.

${ }^{30}$ First proposed in Littlechild (1983). The precise form of the rule varies across enterprises. This detail is ignored here.

${ }^{31}$ Thus, British Telecom has in each year since privatisation except the current one increased its prices by the full amount permitted under the rule. This year however it has not, possibly because of the threat of competition from an alternative supplier, Mercury, but more probably as a public relations exercise given the very bad press it has received on the quality of its services.
} 
rate of price increase determined? The factual answer is: probably rather arbitrarily. ${ }^{32}$ A number of considerations will have been balanced: the possible scope for productivity improvement, recent trends in costs, the likely effect on the stock market valuation of the shares to be issued at privatisation, the political advantages of not appearing to be 'soft' on monopoly, and so on. The more relevant question is: when, after the five year period for which they are initially set has elapsed, the price constraint is reconsidered, how should ${ }^{33}$ it be chosen? We can now consider an agency model of the regulatory process which may provide an answer to this question.

\section{Regulation as agency}

The idea of modelling regulation as an agency problem is of course not new, ${ }^{34}$ but what matters is that the model should capture the essential features of the real situation. Because of space limitations, I set out here a very simple model which nonetheless captures the essential results of the more general analysis in Rees (1987b). Suppose we have a regulated monopoly which maximizes profit ${ }^{35}$ under conditions of increasing average cost, with a cost function $C(y, \theta), C_{\theta}<0$, with $y$ as output and $\theta$ again a productivity parameter. The regulator, who sets a maximum price $p$, knows the demand function $y(p)$ but has only a prior density function on $\theta$, which however is fully known by the monopoly. If the regulator sets $p(\theta)$ according to the rule $p=C_{y}(y, \hat{\theta})$ following a report $\hat{\theta}$ from the monopoly, then this is not incentive compatible, ${ }^{36}$ since the monopoly will report a $\theta$ which implies that $p(\hat{\theta})$ maximises his profit given the true $\theta$. I would argue that this is the case under the current regulatory system in the U.K. The information on which a price constraint ${ }^{37}$ will be based will be supplied by the enterprise there is necessarily an information asymmetry.

Thus, the regulatory process as it stands, just as much as its predecessor, does not solve the 'agency problem'. To solve this problem we need an additional instrument with which to 'bribe' the enterprise to reveal its true $\theta$, and in the present case an obvious instrument ${ }^{38}$ is a levy on pure profits, ${ }^{39}$

\footnotetext{
${ }^{32}$ For example, British Telecom's rule is $R P I-3 \%$. Three is a very cultural number.

${ }^{33}$ Notice the analysis here will be unashamedly normative.

${ }^{34} \mathrm{See}$ in particular Baron and Myerson (1982).

${ }^{35}$ For simplicity I am ignoring the more complicated utility function for the enterprise discussed eariier. Similar results can however be obtained for this case.

${ }^{36}$ As Baron and Myerson, op. cit., show.

37'Since I am dealing here with a static model, it is helpful to translate a constraint on the rate of change of price to one on the level, which of course can be done given the initial price level.

${ }^{38}$ Baron and Myerson used as an instrument a money transfer made by government to the monopoly. The idea of the government making transfers to highly profitable enterprises such as British Telecom and British Gas is not really credible. In other words the details of the regulatory situation in the U.K. do not fit the Baron-Myerson model and a somewhat different approach is called for.

${ }^{39}$ Thus the opportunity cost of shareholders' funds is included in the cost of capital. We are not interested in 'rate of return regulation'.
} 
$T \geqq 0$. A simple diagram can be used to show that under certain quite reasonable assumptions the regulator can in fact achieve a first-best solution. Thus suppose that $\theta$ has two possible values, $\theta_{i}, i=1,2$, the enterprise reports one of these values $\hat{\theta}_{i}$ to the regulator who then sets a maximum price $p_{i}=p\left(\hat{\theta}_{i}\right)$, and also sets a profit levy $T_{i}=T\left(\hat{\theta}_{i}\right)$, subject to the nobankruptcy constraint

$$
\pi\left(p\left(\hat{\theta}_{i}\right), \theta_{i}\right)-T\left(\hat{\theta}_{i}\right) \geqq 0,
$$

so that the enterprise can at least meet all its opportunity costs. In fig. 1a, we see the range of possible prices for $\theta=\theta_{1}$, bounded by $\hat{p}_{1}$, the monopoly price, and $\bar{p}_{1}=C\left(y, \theta_{1}\right) / y$, the minimum price the regulator can set and still expect output ${ }^{40} y>0$. If $\theta_{1}$ were the true value he would set $p_{1}^{*}=C_{p}\left(y, \theta_{1}\right)$. In $1 \mathrm{~b}$ of the figure, $\theta_{1}^{0}$ gives the locus of $\left(p\left(\theta_{1}\right), T\left(\theta_{1}\right)\right)$ pairs which satisfy the no-bankruptcy constraint as an equality. $\theta_{2}^{0}$ shows the equivalent locus for $\theta=\theta_{2}$. If the regulator knew $\theta_{i}$, he could set the corresponding $p_{i}^{*}$ and any profit levy in the interval $\left[0, T_{i}^{*}\right]$. If he does not know $\theta_{i}$, given the assumptions on which the figure is drawn, he can still achieve the first best by offering to set $\left(p_{1}^{*}, T_{1}^{*}\right)$ if $\theta_{1}$ is reported, and $\left(p_{2}^{*}, \hat{T}_{2}\right)$ if $\theta_{2}$ is reported. This induces reporting of the true $\theta_{i}$, and permits marginal cost pricing. To see this, note that if $\theta_{1}$ is true, the enterprise strictly prefers $\left(p_{1}^{*}, T_{1}^{*}\right)$ to

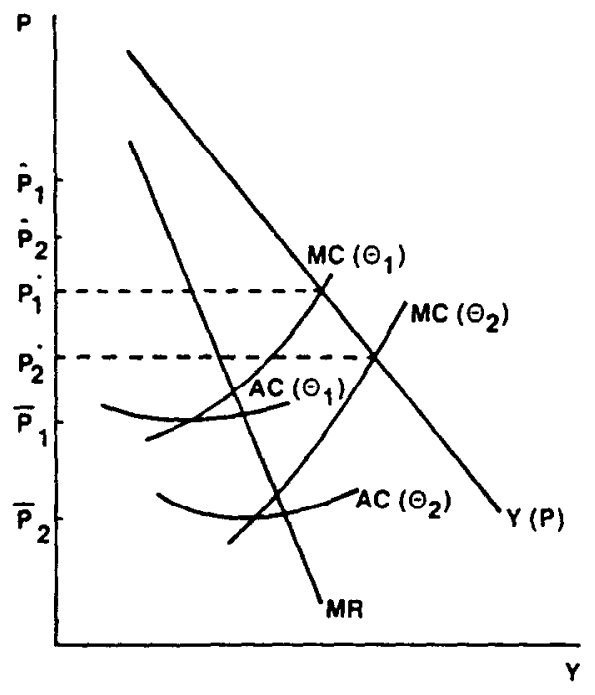

Fig. Ia

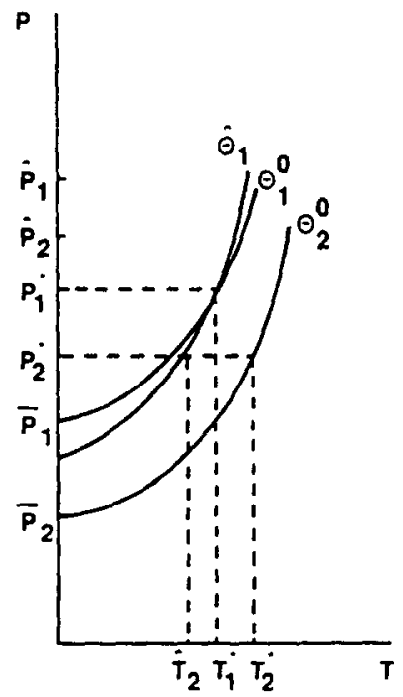

Fig. Ib

${ }^{40}$ Thus, given any price $p^{0}$ set by the regulator, the profit maximizing enterprise chooses output $y^{0}$ such that $p^{0}=C_{y}\left(y^{\circ} \theta\right)$, if $\theta$ is the true state. For $p^{0}<p_{i}^{*}$, this implies that in $\theta_{i}$ output will fall short of demand. 
$\left(p_{2}^{*}, \hat{T}_{2}\right)$ and so will report $\theta_{1}$. If $\theta_{2}$ is true, the enterprise is indifferent between $\left(p_{2}^{*}, \hat{T}_{2}\right)$ and $\left(p_{1}^{*}, T_{1}^{*}\right)$ (given the 'single crossing condition' stated below) and so will report $\theta_{2}$. In effect the regulator bribes the enterprise to reveal itself as having lower costs, when this is true, by allowing it positive profit. Since he is indifferent to the profit of the monopolist, this achieves the first best. The condition which guarantees this result is the single crossing condition', that $\hat{\theta}_{2}$ (the locus of $(p, T)$ pairs satisfying $\left.\pi\left(p, \theta_{2}\right)-T=\hat{T}_{2}\right)$ cuts $\theta_{1}^{0}$ from below. ${ }^{41}$

The main policy implication I would draw from this analysis is that the regulatory framework so far constructed for privatised monopolies in the U.K. is seriously incomplete, since it encourages manipulation and false reporting by the enterprises concerned. If it is extended to include lump sum taxation on pure rents, then the first best ${ }^{42}$ may be available.

\section{Conclusion}

This attempt to analyse the inefficiency of public enterprises and the potential inefficiency of their privatised, regulated counterparts leaves a number of issues for further analysis. In particular, the enterprise utility function is something of a 'black box', and more analysis of the nature of the intra-firm bargaining equilibrium is required. A great deal of insight of a positive rather than normative kind could also be gained by replacing the assumption that the principal is interested only in allocative efficiency with a more realistic characterization of the objective function. My hope is however that enough will have been done to convince economists working on problems of public enterprise, privatisation and regulation that an approach through agency theory is a potentially fruitful one.

\footnotetext{
${ }^{4}$ It can be shown that this condition requires only that marginal cost be decreasing in $\theta$, which is a reasonable condition to impose on the problem.

${ }^{42}$ If the regulator is not indifferent to the value of $T$, then in general the first-best (in terms of his preferences) is not available.
}

\section{References}

Baron, D.P. and R.B. Myerson, 1982, Regulating a monopolist with unknown costs, Econometrica 50, 911-930.

Bös, B., 1988, Public enterprises in theory and practice, European Economic Review, this issue. Caillaud, B., R. Guesnerie, P. Rey and J. Tirole, 1985, The normative economics of government intervention in production, Mimeo. (IMS.S.S., Stanford, CA).

Guesnerie, R. and J. Laffont, 1984, Control of public firms under incomplete information with an application to a self-managed public firm, Journal of Public Economics 25, 329-369.

Henderson, P.D., 1977, Two British errors: Their probable size and possible lessons, Oxford Economic Papers 29, 159-203.

Littlechild, S.C., 1983, Regulation of British Telecommunications' profitability (Department of Industry, London). 
MacDonald, G.M., 1984, New directions in the economic theory of agency, Canadian Journal of Economics, 17, 415-440.

Myerson, R.B., 1979, Incentive compatibility and the bargaining problem, Econometrica 47, 6!73.

Perelman, S. and P. Pestieau. 1988, Technical performance in public enterprises: A comparative study of posts and railways, European Economic Review, this issue.

Rees, R., 1984a, A positive theory of the public enterprise, in: M. Marchand, P. Pestieau and H. Tulkens, eds., The performance of public enterprises (North-Holland. Amsterdam).

Rees, R., 1984b, The public enterprise game, Economic Journal, 94, 109-123.

Rees, R., 1985a. The theory of principal and agent, parts 1 and 2, Bulletin of Economic Research, 27, 3-26 and 75-95.

Rees, R., 1985b, Principal-agent theory and public control of production, Mimeo. (University College, Cardiff, 8514).

Rees, R., 1986a, Incentive compatible public sector discount rates, Journal of Public Economics, 30, 249-258.

Rees, R. 1986b, Is there an economic case for privatisation?, Public Money, March.

Rees, R., 1987a, Modelling public enterprise performance, in: D. Helm, J. Kay and D. Thompson, eds., The market for energy (Oxford University Press, Oxford).

Rees, R., 1987b, Regulation in the U.K.: An agency approach, Mimeo. (University of Guelph, Guelph). 